\title{
Groundwater resource-directed measures software
}

\author{
Ingrid Dennis ${ }^{1 *}$ and Johan Wentzel ${ }^{2}$ \\ 1 Institute for Groundwater Studies, University of the Free State, PO Box 339, Bloemfontein, 9300, South Africa \\ ${ }^{2}$ Department of Water Affairs and Forestry, Private Bag X313, Pretoria, 0001, South Africa
}

\begin{abstract}
Sustainability, equity and efficiency are identified as central guiding principles in the protection, use, development, conservation, management and control of water resources. These principles recognise the basic human needs of present and future generations, the need to protect water resources, the need to share some water resources with other countries, the need to promote social and economic development through the use of water, and the need to establish suitable institutions in order to achieve the purpose of the National Water Act (Act No. 36 of 1998). To be able to implement the National Water Act (NWA), the Minister needs to ensure that the tools and expertise required to implement the Act are available. The Department of Water Affairs and Forestry (DWAF) set about developing the required methods and procedures to comply with the provisions set out in the Act. The classification of a resource is the starting point of the process.

The Reserve, a provision in the Act that requires water to be set aside for basic human needs and aquatic ecosystems before allocation to other users, is based on classification. Protection measures that cannot be accommodated in the Reserve are accommodated in resource quality objectives which are based on both the classification and the Reserve. This approach is particularly relevant to groundwater, since the Reserve only relates to basic human needs and aquatic ecosystems and does not make provision for the protection of resources that are not linked to these uses. As part of addressing this issue, software was developed to assist in resource assessments, with the focus on all three components that need to be assessed. A case study is used to demonstrate how the software can be used to assist in resource assessments.
\end{abstract}

Keywords: resource units, classification, reserve, resource quality objectives

\section{Introduction}

To be able to implement the National Water Act (Act No. 36 of 1998), the Minister needs to ensure that the tools and expertise required to implement the Act are available. There is a dire need for training in groundwater resource assessment, with emphasis on resource-directed measures. This was addressed in 2004 and 2005 by Roger Parsons and Johan Wentzel who compiled a training manual (funded by the Water Research Commission, FETWATER and DWAF). To assist in training and assessment, DWAF: Resource Directed Measure Directorate requested the Institute for Groundwater Studies to develop Groundwater Resource Directed Measures (GRDM) software. In this paper the methods developed for the GRDM together with the software package developed for groundwater resource-directed measures are discussed in detail. The software together with the manual can be obtained from the following DWAF user support website: www.usersupport. co.za.

\section{NWA and GRDM}

The objective of GRDM is to facilitate the proactive protection of the country's groundwater resources in line with sustainability and equity principles as the NWA recognises the need to develop and use water resources to grow. However, the NWA also recognises that the water resources should not be used to the detriment of future users. GRDM hence strives to ensure that groundwater resources are afforded a level of protection that

* To whom all correspondence should be addressed.

용 +27 51 401-3481; fax: +27 51 444-6538;

e-mail: dennisi.sci@mail.uovs.ac.za

Received 21 July 2006; accepted in revised form 5 October 2006. will assure a sustainable level of development for the future. To this end, GRDM comprises four main interrelated components, namely:

\section{Delineation of resource units}

The NWA states that the Minister must determine the Reserve for all or part of every significant water resource. The basic unit of any Reserve-related assessment is the quaternary catchment. It may, however, be necessary divide a quaternary catchment further into resource units (RUs), which are areas of similar physical (for example geology) or ecological (for example groundwater dependence) properties, grouped or typed to simplify the Reserve determination process.

\section{Classification}

The key outcome of this phase is to classify each RU in terms of the desired management class (excellent, good, fair). In essence, the classification process aims to define a resource in its natural state, assess its current state and levels of its development and use, and define the future desired state of the resource. A range of factors can be considered, including recharge, groundwater use, contamination, or potential contamination status. The classification of a resource therefore includes (amongst others) the following aspects:

- Ecological Reserve

- Basic human need Reserve

- Other water use requirements

- Stakeholder engagement.

\section{The Reserve}

By definition, only part of the groundwater system is included 


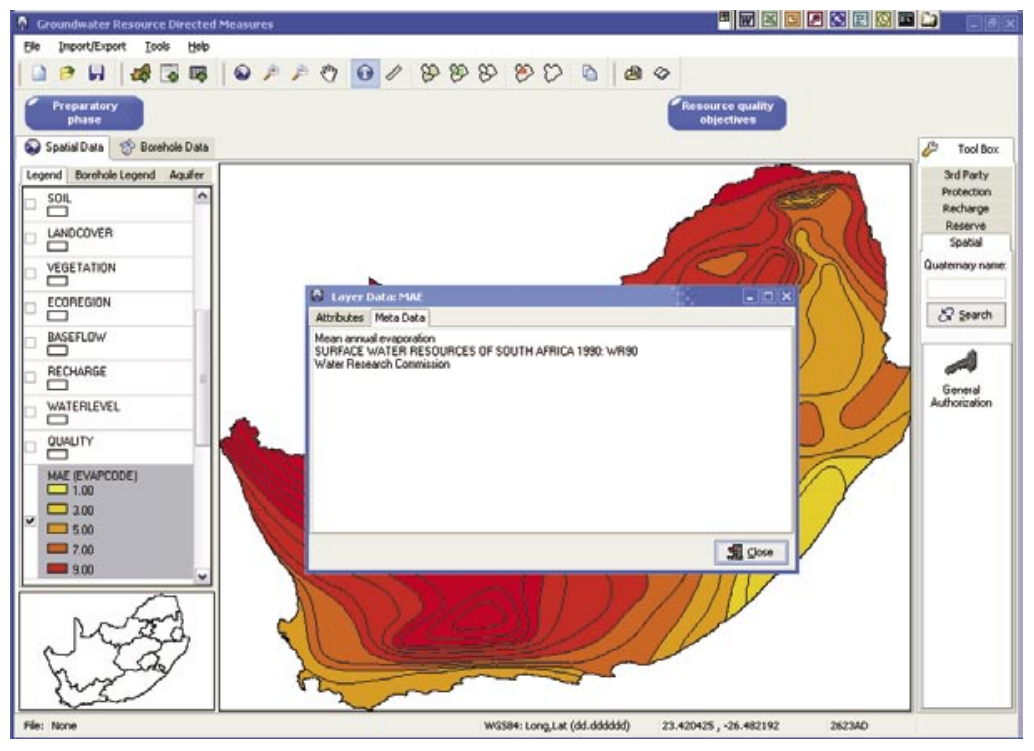

Figure 1

Metadata screen for mean annual evaporation

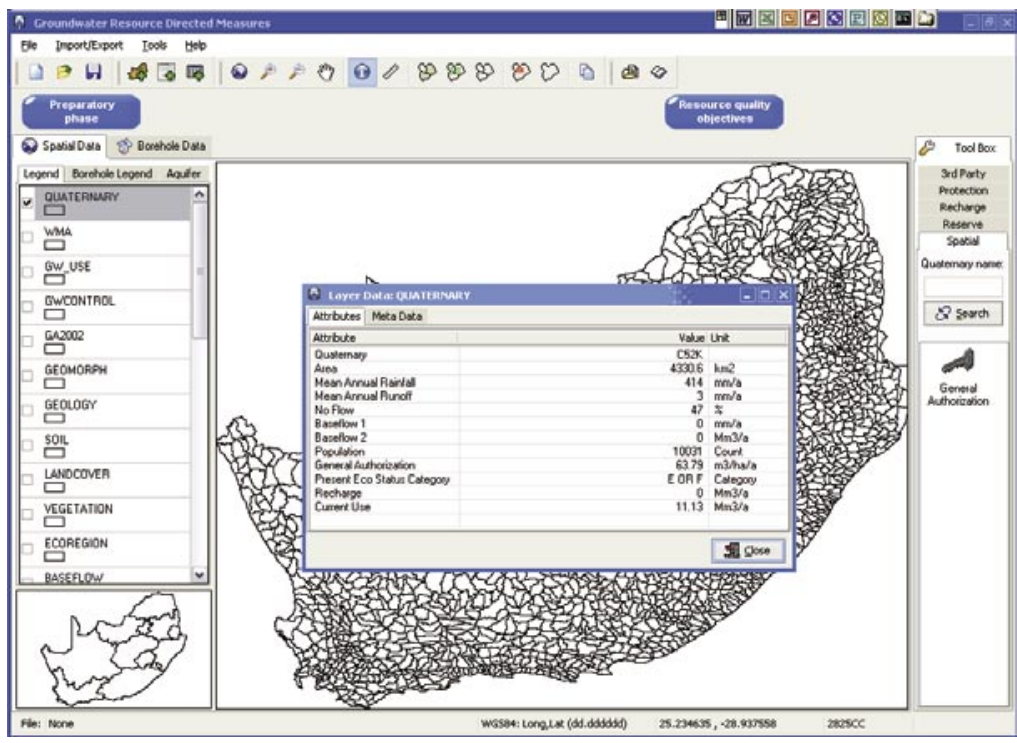

Figure 2

Attribute data for the quaternary shape file

in the Reserve. Where groundwater contributes to or supports basic human needs or aquatic ecosystems, groundwater forms a component of the Reserve and hence has to be considered. However, groundwater also occurs in areas away from aquatic ecosystems and supports other components of the environment that may not form part of the Reserve. In such instances, groundwater protection is mainly affected through classification and resource quality objectives (RQOs).

\section{Resource quality objectives}

These are clear guidelines that balance the need to protect and sustain a water resource with the need to develop and use it and it is based on both the Reserve requirements and classification. At the same time as setting the Reserve for all water resources in the country, DWAF will determine RQOs for each significant water resource. These objectives will tell managers how much water is needed to keep a water resource healthy and what the quality of the water should be. The outcome of this phase is a list of goals - either numeric or descriptive - that can be used to set aquifer management criteria.

\section{GRDM Software}

\section{Background}

The GRDM software is a stand-alone package developed in Borland $\mathrm{C}++$ Builder with Windows ${ }^{\circledR} 9 \mathrm{x}, \mathrm{NT}, 2000$ and XP as target platforms. The software utilises a local MS Access database, but MS Access is not a prerequisite for the software. The GIS functionality is provided through the use of ESRI Map Objects Lite 2.0, which is embedded in the software, thus making the application $100 \%$ compatible with the ESRI shape file format and geo-referenced images.

\section{Spatial and non-spatial data sets}

To assist the user in an assessment, a number of shape files have been included in the software. These include:

- Water management areas

- Groundwater use

- Groundwater control areas

- General authorisations 
Figure 3

Importing borehole data

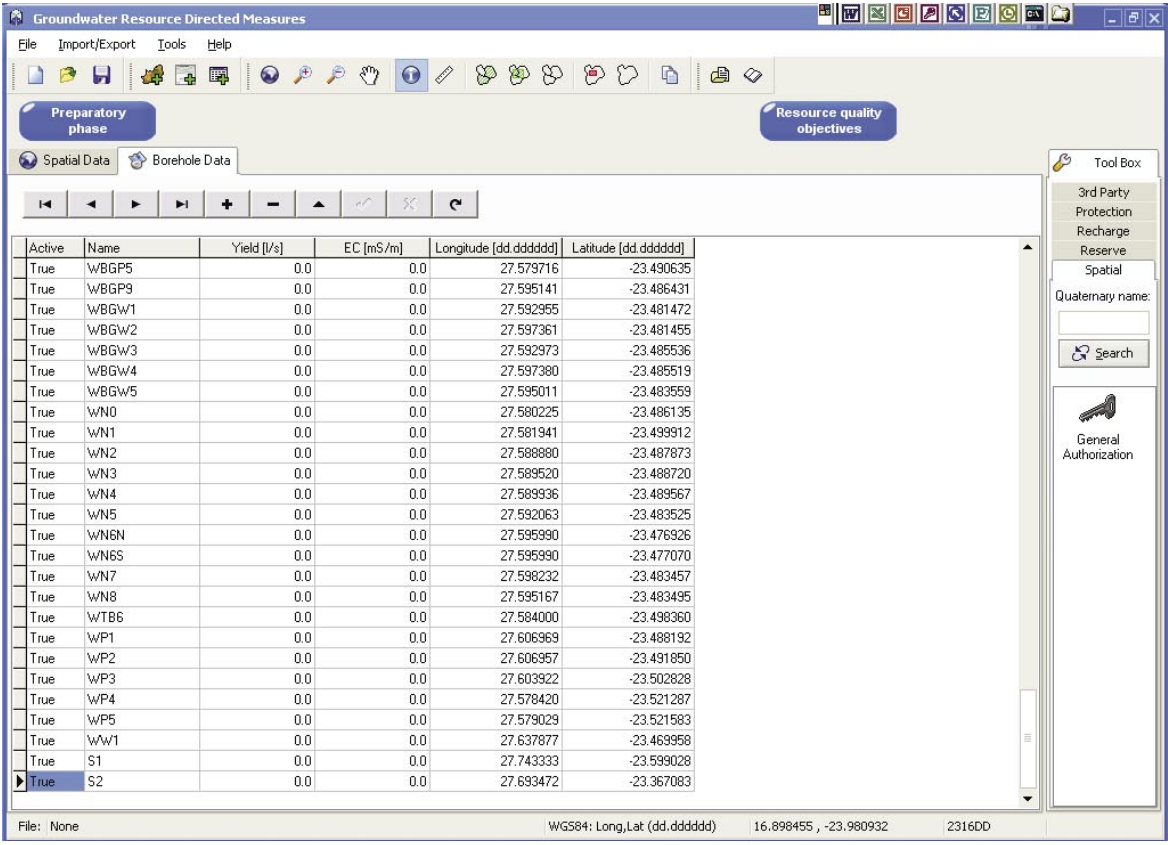

Preparatory Phase $\quad x$

General 49 Impact of License

A GRDM study can be initiated by DWAF Head Office as part of the compulsory licensing process, or by a DWAF Regional Office in response to a license application or anticipated application. This is largely a management task, with specialist groundwater input being provided by DWAF personnel.

As a means of initiating the study and setting the level of GDRM assessment required land hence Terms of Referencel, it is recommended a desktop GRDM assessment be undertaken. In some cases, a Scoping

Figure 4

Preparatory phase

Study can be undertaken if more detailed information is required before the level can be set.

\begin{tabular}{|c|c|c|c|c|c|c|}
\hline Assessor & & & 㽣 & \multicolumn{3}{|c|}{ Level of Assessment } \\
\hline \multicolumn{7}{|l|}{ Affiliation } \\
\hline \multirow[t]{2}{*}{ Aquifer type } & Major Aquifer & $\nabla$ & & Rapid & Cor & hensive \\
\hline & & & & & $\sum$ Undo & $\checkmark$ Accept \\
\hline
\end{tabular}

- Geomorphology

- Geology

- Soil

- Land cover

- Vegetation

- Water level

- Water quality

- Mean annual evaporation

- Dams

- Rivers

- Roads

- Topography

- Provinces

- Towns

- Flow stations

- Ecoregions

- Baseflow

- Quaternary catchments (including rainfall, runoff, recharge, etc. per catchment)
The metadata for each of the above-mentioned shape files have been incorporated in the software. For example, see Fig. 1 for the metadata for mean annual evaporation. In addition, by clicking on the information button on the toolbar, the user can obtain the attribute information associated with a specific shape file. Figure 2 shows the attribute data for the quaternary shape file.

The user can import borehole data (name, yield, water quality and coordinates), as shown in Fig. 3. The software can plot the boreholes on the spatial layers, together with their radius of influence and classification of groundwater, according to the South African Water Quality Guidelines (SABS 241, 2001).

Users can also import their own shape files and geo-referenced images such as the 1:50 000 South African topography maps.

\section{Preparatory phase}

Once DWAF Head Office or DWAF Regional Office has initiated a GRDM study, the following has to take place:

- The area to be studied has to be defined 


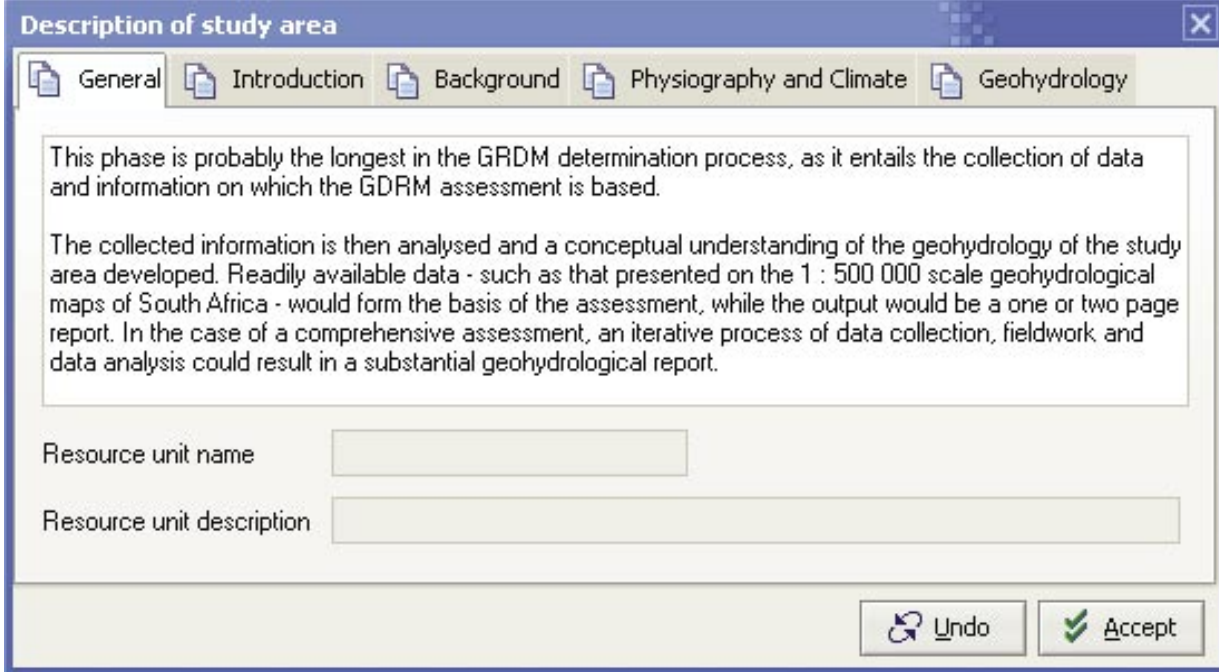

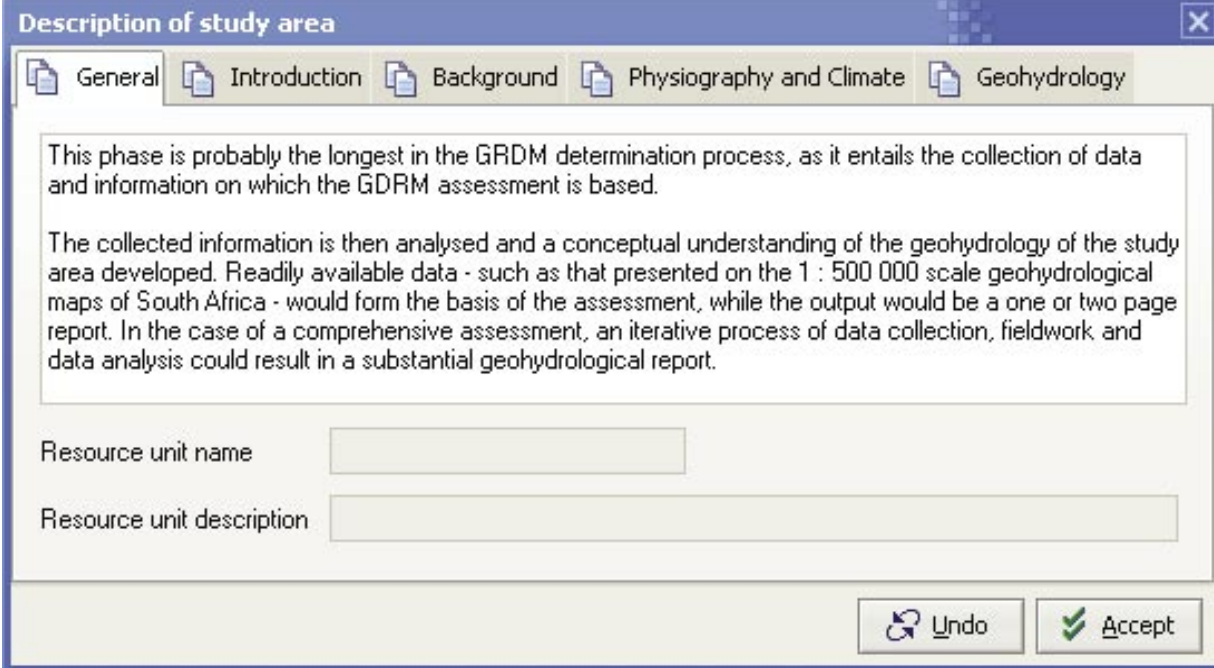

Figure 5

Description of the study area

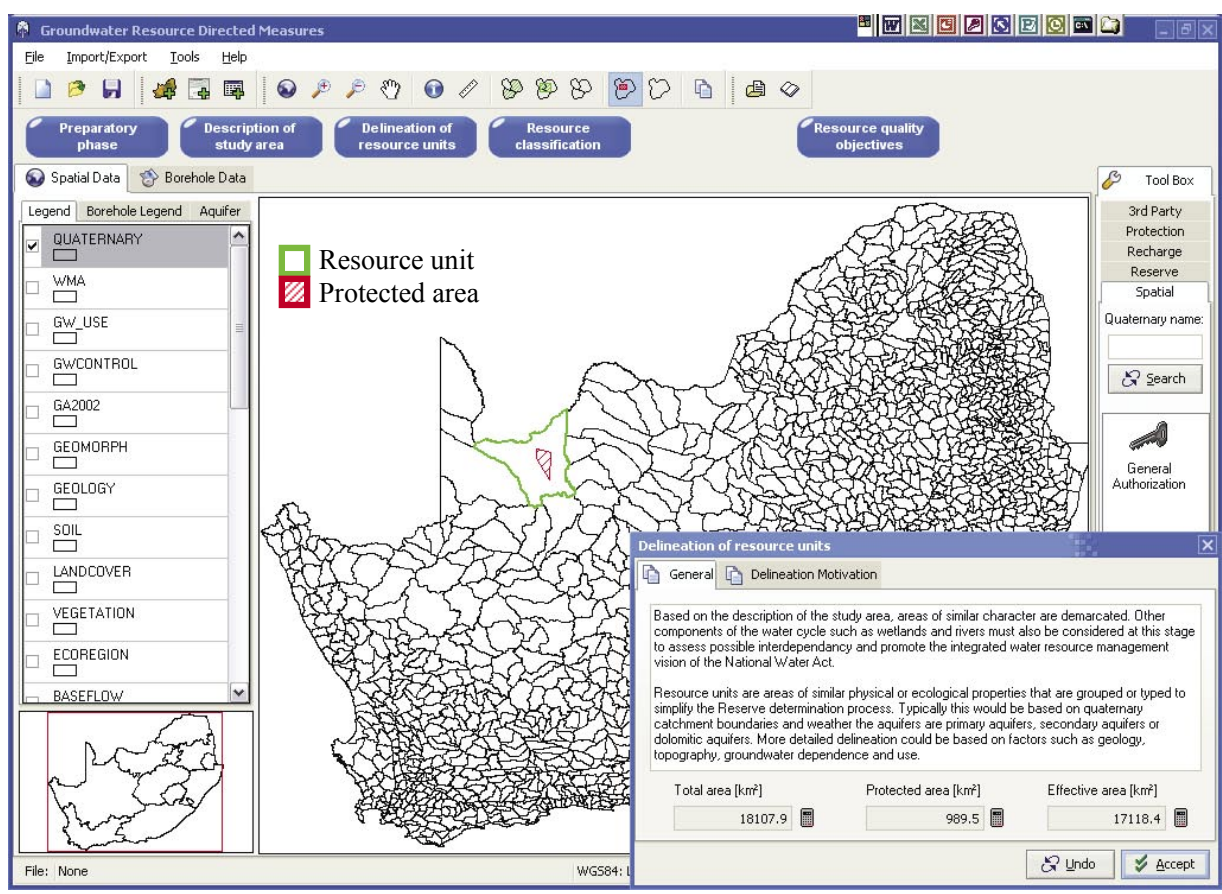

Figure 6

Delineation of resource units
- The level of confidence of the study has to be set

- The study team to undertake the assessment must be appointed

- Key issues concerning the assessment (for example licensing, current use, strategic issues, type of aquifer) have to be identified.

The GRDM software assists the user in this process (see Fig. 4), providing a number of menus and text boxes to provide the abovementioned information. This information will be saved and later automatically exported to a report generated by the software.

\section{Description of the study area}

This phase entails the collection of data and information on which the GRDM assessment is based. The collected information is then analysed and a conceptual understanding of the geohydrology of the study area developed. Maps included in the software can form the basis of the assessment. Once again the software guides the user through this process by including text boxes in which information can be captured (see Fig. 5).

\section{Delineation of resource units}

The key outcome of this step is a map demarcating groundwater RUs, each of which is to be classified, a Reserve assessment undertaken and RQOs set. This map can be exported as a bitmap. In delineating groundwater resource units, consideration must also be given to the role of groundwater in the environment. The software allows the user to select a single or multiple quaternary catchments as a resource unit or a custom area. Protected areas within the resource unit can also be delineated and excluded from the study (Fig. 6). The motivation (be it geology, topography, etc.) for selecting the RU can also be documented here.

\section{Resource classification}

A water resource category must be determined for each ground- 


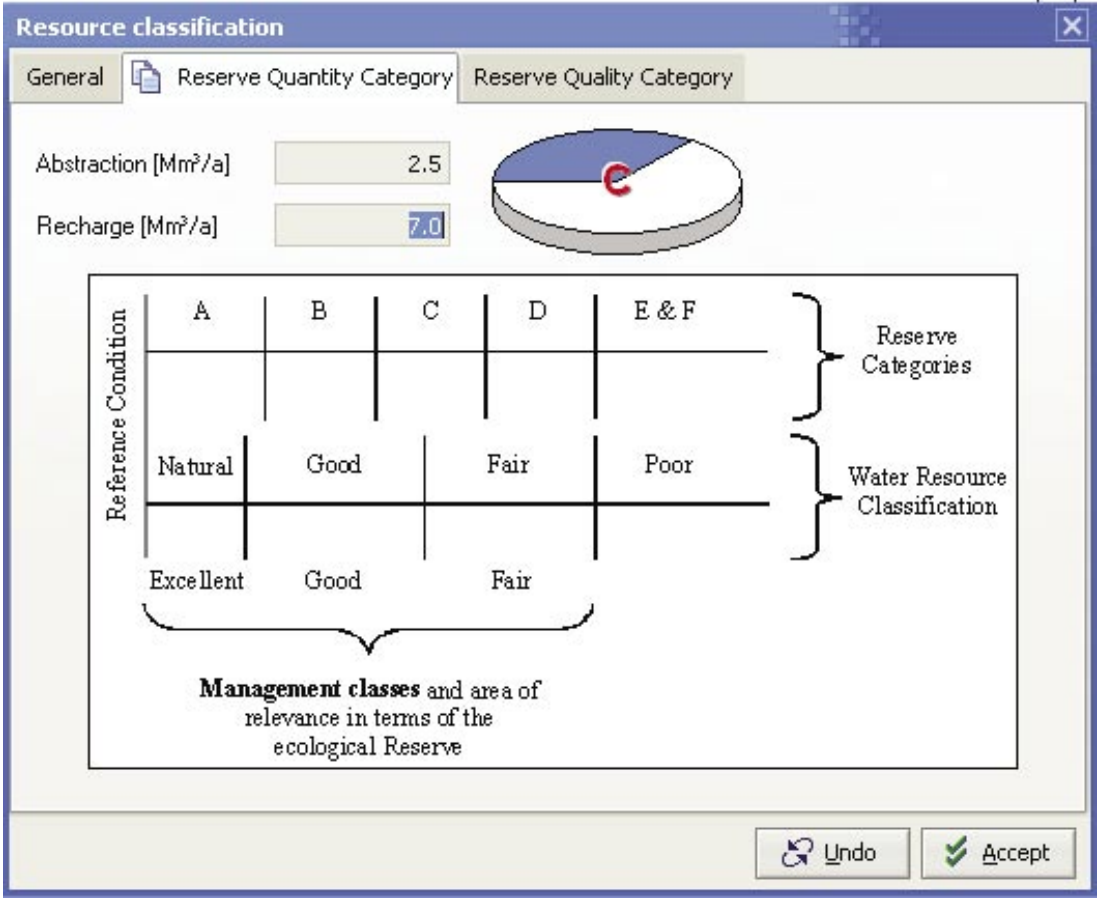

Figure 8

Baseflow separation

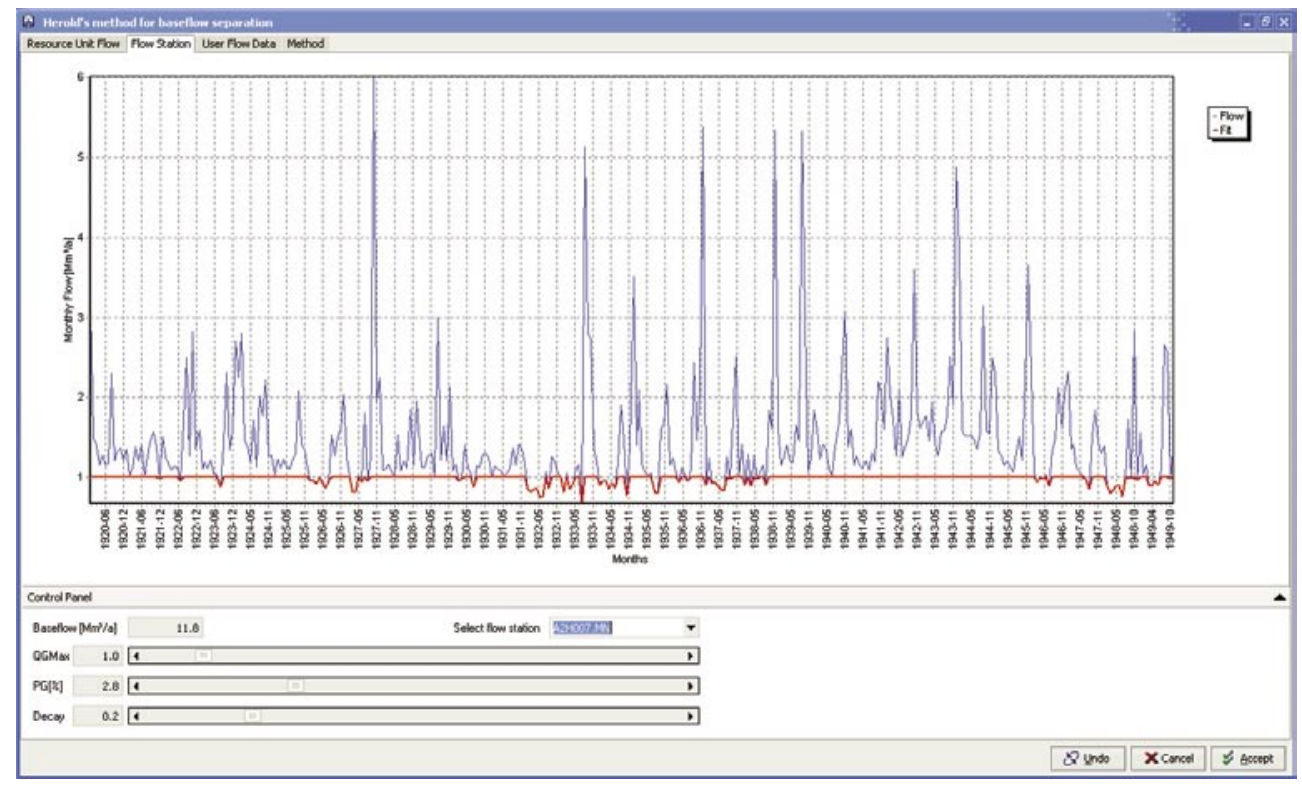

water resource unit. To do this, one has to consider both ambient or reference conditions and the present status of each unit.

Parsons (2005) suggested using a stress index, which is converted to a resource category. The stress index is calculated by dividing the total abstraction in the resource unit by the recharge for the resource unit (Fig. 7). A category is then allocated as follows:

\begin{tabular}{|c|c|}
\hline Category & Percentage stress \\
\hline A & $<5$ \\
\hline B & $5-20$ \\
\hline C & $20-40$ \\
\hline D & $40-65$ \\
\hline E & $65-95$ \\
\hline F & $>95$ \\
\hline
\end{tabular}

In addition to the stress index, tables have been included in the software to assist the user in determining a water quality category if no other information is available. These tables include degree of impact due to abstraction and water quality deterioration, aquifer vulnerability and land use.

\section{Quantification of the Reserve}

Where groundwater contributes to or supports basic human needs or aquatic ecosystems, groundwater forms a component of the Reserve and hence has to be considered. The software calculates the groundwater component of the Reserve for basic human needs and aquatic ecosystems. The Reserve is then expressed as a percentage of recharge to the RU. The allocatable amount of groundwater for the RU is also calculated. 


\section{Resource quality objectives}

At present no formal guidelines exist with respect to setting RQOs. The Water Research Commission conducted a study to develop guidelines (Colvin et al., 2003). RQOs can include any requirement or condition that may need to be met to ensure that the groundwater resource is maintained in a desired and sustainable state as defined in the classification process. However guidelines have been included in the GRDM. RQOs guidelines have been set for groundwater interaction with rivers, wetlands, estuaries, springs, protected areas, strategic use/international obligations, basic human need boreholes and karst aquifers. Each of these will be discussed in more detail:

1. Rivers can be groundwater-fed and/or have riparian vegetation. Perennial rivers and non-perennial rivers with pools are normally fed by groundwater and therefore need to be protected by means of RQOs. The amount of groundwater flowing into the river needs to be calculated for this (i.e. groundwater contribution to baseflow). Once this has been established the RQO can be set as a groundwater level or gradient that must be maintained for a certain distance from the river.

2. To determine the RQOs for wetlands/estuaries, the amount of groundwater flowing into these regions needs to be calculated. Once this has been calculated the RQO can be set as a groundwater level or gradient that must be maintained for a certain distance from the wetland/estuary.

3. Groundwater-driven springs and associated ecosystems have to be protected. However, the way in which they are protected differs between hot and cold springs. Hot or thermal springs according to Kent (1949) are those for which the water temperature is above $30^{\circ} \mathrm{C}$. Their groundwater source is usually very deep below the earth's surface. Boreholes must therefore not intercept these aquifers and deplete the source of these springs. The geothermal gradient for groundwater, that is, the rate of increase in temperature with depth, is about $1^{\circ} \mathrm{C}$ per $30 \mathrm{~m}$ depth (Van Tonder, 2006) although there are exceptions to the rule.

The capture area for a cold water spring can be determined using standard methods. A minimum distance for any potentially harmful activities (boreholes, possible pollution sources) must be allocated outside the minimum distance.

4. Groundwater use for basic human needs, strategic use and for international obligations must also be protected. The recommended abstraction rates in the boreholes or flow across international boundaries must be calculated and protection zones delineated.

Once this has been calculated the RQO can be set as a groundwater level or gradient that must be maintained for a certain distance or as an assurance of supply (sustainability) of the groundwater resource.

5. RQOs also need to be assigned to protected areas such as national parks and world heritage sites. The amount of groundwater flowing into these regions needs to be calculated. Once this has been calculated the RQO can be set as a groundwater level or gradient that must be maintained for a certain distance from the protected area.

6. Because of the number of subsidence areas and sinkholes forming in South Africa due to abstraction in Karst aquifers, it was decided to set RQOs for these aquifer systems. In Karst aquifers the RQO is set as follows: the groundwater level may not vary by more than $2 \mathrm{~m}$ with time.

\section{Toolbox}

Under this menu there is a scientific calculator, the software Tripol for generating groundwater contours and a unit conversion tool. A toolbox occurs on the right-hand side of the screen in the GRDM software. There are five sub-menus under the toolbox menu:

- $\quad 3^{\text {rd }}$ Party software: Under this menu there is a scientific calculator, the software Tripol for calculating groundwater contours and a unit conversion tool.

- Spatial menu: Allows the user to search for and highlight quaternary catchments.

- Reserve menu: Allows the user to do baseflow separation using Herold's method (Herold, 1980) (Fig. 8). Tools are also available to calculate groundwater inflow and outflow and groundwater draw-downs.

- Recharge menu: Allows the user to calculate groundwater recharge using one of the following methods: Earth method, chloride method, isotopes, cumulative rainfall departure method, saturated volume fluctuation method.

- Protection method: Includes tools for the user to calculate the radius of influence of a borehole, protection area around a borehole, river, coast and wetland.

Help-screens have been included for all tools to assist the user in understanding the calculations.

\section{Additional functions}

All information (including that documented in text boxes) is automatically saved in a report, which can be opened and edited in a Word document. Bitmaps can also be saved. A dictionary has been included, as well as the GRDM manual. The user can access these by clicking on icons on the toolbar at the top of the screen.

\section{Case study}

\section{Preamble}

The Kromme River Catchment is located in the Eastern Cape, South Africa, to the west of Jeffreys Bay. The Kromme River is located in a narrow plane between the Suuranys and Tsitsikamma Mountains, is approximately $95 \mathrm{~km}$ long and drains a catchment area of $1125 \mathrm{~km}^{2}$. It runs in an easterly direction and exits into the Indian Ocean at St Francis Bay. The groundwater flows towards the Kromme River. The study area (quaternary catchment K90A) focuses along the first $30 \mathrm{~km}$ of the Kromme River (Fig. 9). There are approximately 259 people living in this area, some of which are dependent on groundwater for their basic human needs. In addition, there are sensitive groundwater-fed wetlands along this stretch of the Kromme River. Bulrushes have various important functions in the wetland systems of the Kromme River, such as maintaining surface water flow, reducing erosion and maintaining ecological systems. The area is also home to indigenous fynbos, referring to a distinctive community of plants found in the South Western Cape. Many of these plants have small, fine stems and leaves. The vegetation has a bushy appearance.

Agricultural activities are destroying the riparian zone and alien vegetation (especially Black Wattle trees - Acacia mearnsii) is impacting groundwater and wetlands, and therefore the Kromme River flow. As the Kromme River is one of the main sources of clean drinking water for growing urban areas in adjacent catchments, it is vital that these groundwater-fed wetlands be preserved as they in turn preserve ecosystems related to the river flow. 
Figure 9

Study area

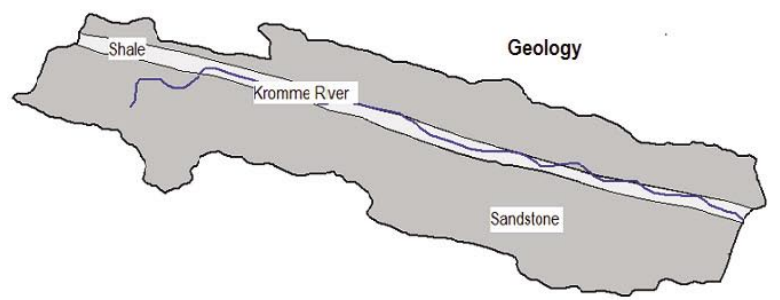

\section{Groundwater Resource Directed Measures}

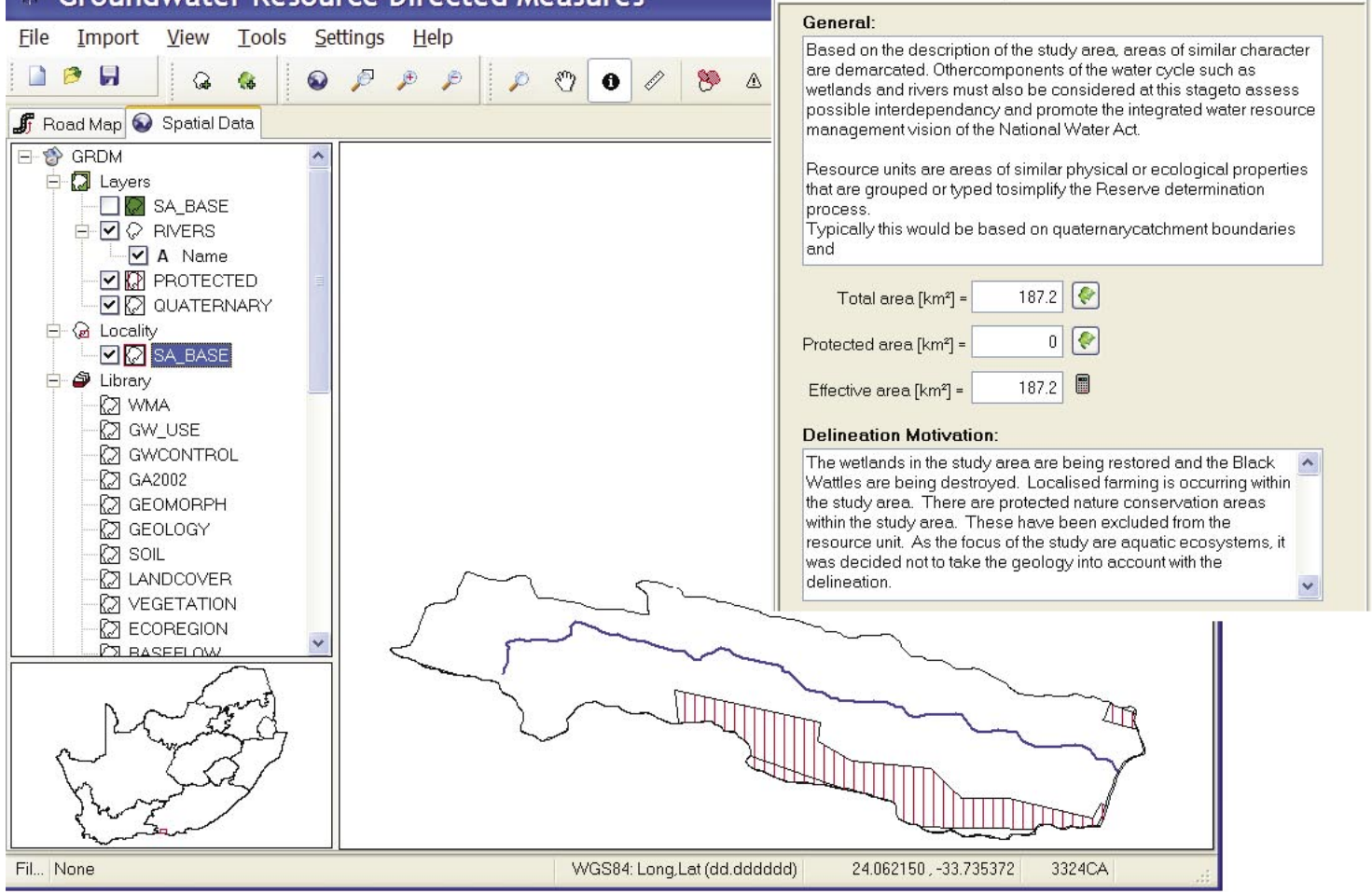

Figure 10

Resource unit (hashed areas excluded protected areas) neation of Resource Unit

Genera:

Based on the description of the study area areas of similar character wands and rivers must also be considered at his stach to the integreded weter resource anagement vision of the National Water Act this would be based on quaternarycatchment boundaries

$\begin{aligned} \text { Total area }\left[\mathrm{km}^{2}\right] & =187.2 \\ \text { Protected area }\left[\mathrm{km}^{2}\right] & =0\end{aligned}$
to

GEOLOGY BASEFION
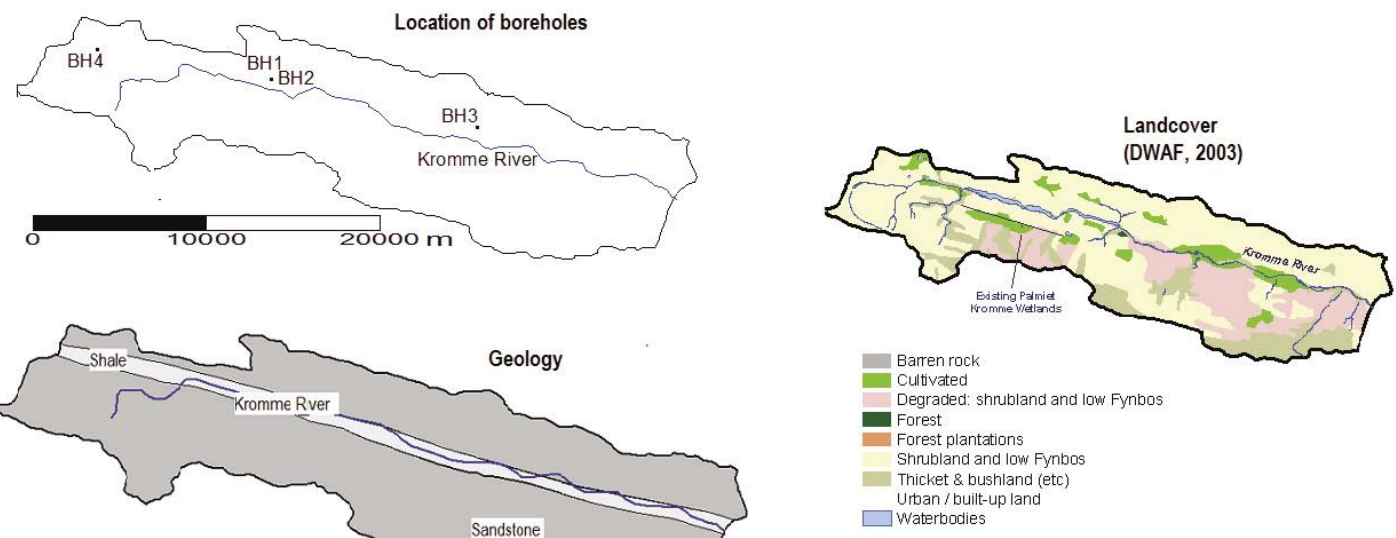

The aim of this case study is to conduct a groundwater resource-directed measure study for this area.

\section{Delineation of resource units}

The wetlands in the study area are being restored and the Black Wattles are being destroyed. Localised farming is occurring within the study area. There are protected nature conservation areas within the study area. These have been excluded from the resource unit. As the focus of the study is aquatic ecosystems, it was decided to place emphasis on this aspect and not the geology in the delineation. The delineated resource unit is shown in Fig 10.

\section{Classification}

The study area is classified according to the table below:

\begin{tabular}{|l|l|l|l|l|}
\hline $\begin{array}{l}\text { Resource } \\
\text { Unit }\end{array}$ & Sustainable use & Level of stress & Usage or contamination & Final category \\
\hline RU1 & $\begin{array}{l}\text { Localised low level } \\
\text { impacts (localised farming } \\
\text { activities), but no negative } \\
\text { effects apparent - B }\end{array}$ & $\begin{array}{l}\text { System recovering being } \\
\text { stressed due to Black Wat- } \\
\text { tle infestation - Slightly } \\
\text { stressed - B }\end{array}$ & $\begin{array}{l}\text { Low volume groundwater } \\
\text { usage, largely natural condi- } \\
\text { tions, no negative impacts } \\
\text { apparent. Largely natural } \\
\text { groundwater quality conditions } \\
\text { prevail. Aquifer has a low } \\
\text { vulnerability - B }\end{array}$ & B \\
\hline
\end{tabular}




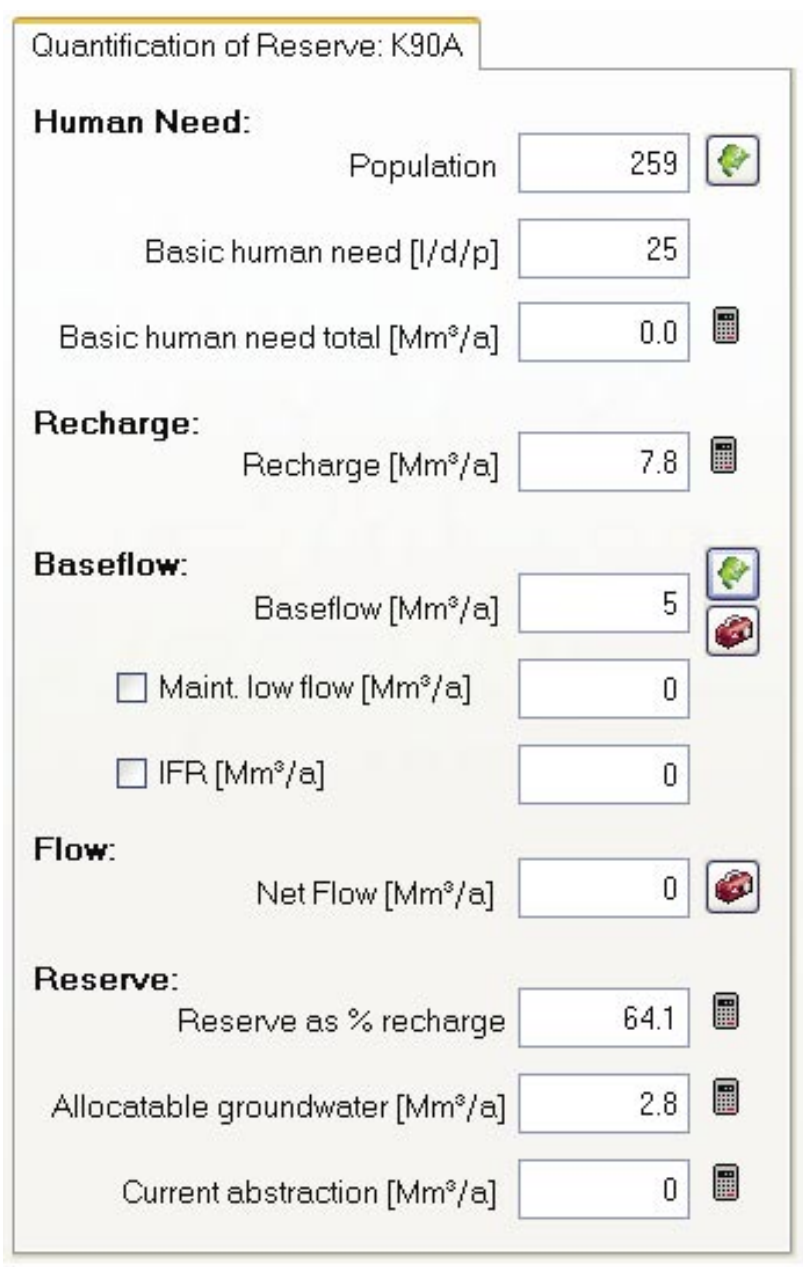

Figure 11

Calculation of the Reserve

Once a single present status category has been assigned to each resource unit, the groundwater resource category can be determined as documented in the table below. It must be remembered that the desired status of the resource and management class is not addressed here, but rather in the public participation and catchment visioning processes.

\begin{tabular}{|l|l|l|}
\hline $\begin{array}{l}\text { Resource } \\
\text { Unit }\end{array}$ & $\begin{array}{l}\text { Resource } \\
\text { category }\end{array}$ & Explanation \\
\hline RU1 & Natural & $\begin{array}{l}\text { Highly sensitive systems, negligible } \\
\text { risk allowed }\end{array}$ \\
\hline
\end{tabular}

\section{Quantification of the reserve}

The groundwater component of the Reserve is the part of the groundwater resource that sustains basic human needs and aquatic ecosystems. The groundwater Reserve is usually expressed as a percentage of the recharge within the resource unit. The results of the quantification are shown in Fig. 11.

\section{Resource quality objectives}

The RQOs for the study area can be summarised as:

- Natural groundwater levels must be maintained $700 \mathrm{~m}$ from the Kromme River to ensure, the wetlands/baseflow along the river are not impacted by abstraction.

- No sources of contamination may occur within a $1000 \mathrm{~m}$ distance from these wetlands and the river.

- There are few BHN boreholes in the study area. These boreholes must be protected with a radius of influence $750 \mathrm{~m}$.

\section{Conclusions}

This paper introduced a tool that can be used to assist in groundwater resource assessments. The aim of the software is to provide the assessor with available information/data and tools to assist in the calculations and assessment of a specific resource. In addition, the text boxes provided in the software allow the assessor to capture his/her reasoning/motivations. All captured information together with the calculations can then be exported to a report that can then be edited in a word document.

\section{Acknowledgements}

- Roger Parsons for developing the GRDM methodology applied in the software and testing the software

- The Water Research Commission, FETWATER and DWAF for financially supporting the development of the software

- Rainier Dennis for coding the software

- Gerrit van Tonder for assisting in developing the RQO guidelines.

\section{References}

COLVIN C, XU Y, VAN TONDER GJ, HUGHES S, LE MAITRE D, ZHANG J, MAFANYA T and BRAUNE E (2003) Towards the Resource Directed Measures: Groundwater Component. WRC Report No. 1090-2/1/03. Water Research Commission, Pretoria, South Africa.

DEPARTMENT OF WATER AFFAIRS AND FORESTRY (2003) Tsitsikamma to Coega Internal Strategic Perspective. DWAF Report No. PB0000/00/0203. Prepared by Ninham Shand on behalf of the Directorate Water Resources Planning (South).

HEROLD C (1980) A Model to Compute a Monthly Basis Diffuse Salt Loads Associated with Runoff. HRU Report No. 1/80. Rhodes University, Grahamstown.

KENT LE (1949) The thermal waters of the Union of South Africa and South West Africa. Trans. Geol. Soc. Afr. 52 231-264.

NATIONAL WATER ACT (1998) Government Gazette, 19182. Act 36, 26 August 1998. Pretoria, South Africa.

PARSONS R (2005) Personal communication. Parsons and Associates Specialist Groundwater Consultants, PO Box 2606, Somerset West.

SABS 241 (2001) South African Standard Specification: Drinking Water $\left(5^{\text {th }}\right.$ edn.). The South African Bureau of Standards, ISBN 0626-12908-7.

VAN TONDER GJ (2006) Personal communication. Institute for Groundwater Studies, University of the Free State, PO Box 339, Bloemfontein. 